\title{
LITTER SIZE AND PROPORTION OF FEMALES IN THE OFFSPRING OF MULTIPAROUS RATS WITH VARYING UTERINE METABOLIC LEVELS*
}

\author{
A. B. SCHULTZE \\ Department of Dairy Science, \\ University of Nebraska, Lincoln, Nebraska, U.S.A.
}

(Received 1st March 1965)

\begin{abstract}
Summary. The rate of TTC reduction by the uterine tissue of rats was determined at specific stages of the oestrous cycle, and in successive cycles at the same stage. Individual females showed a characteristic level of reaction to TTC. Mothers whose uteri had a high reaction rate with TrC produced litters with a higher percentage of female pups than did mothers with a low level of reaction. Previous studies have shown that TTC reduction rate represents a metabolic activity of uterine tissue that is induced by oestrogens.
\end{abstract}

The reduction of triphenyltetrazolium (TTC) to formazan by the vaginal lining of the mouse has been suggested as a biological assay for oestrogens (Martin, 1960), since the rate is proportional to the extent of oestrogenic stimulation. The reaction is not promoted by progesterone, testosterone or cortisol. Schultze (1964) showed that, when uterine segments from spayed rats were incubated with TTC, the TTC was reduced to formazan at a rate proportional to the dosage of oestradiol administered. Furthermore, TTC reduction by uterine segments from intact cycling females was significantly higher at the pro-oestrous stage of the cycle than at other stages. Thus the level of the rate of reduction of TTC brought about by reaction with uterine tissue may be considered as a quantitative estimate of oestrogenic effects. In the present study it has been used as an index of the oestrogen status of the uterus, and examined in relation to reproductive performance.

The first part of this study was made to find out whether there are significant differences among normal intact female rats in the ability of their uteri to reduce Trc. Even though the rate of this reaction varies with the oestrous cycle, is the degree of oestrogenic stimulation maintained at a higher level in some females than in others? For this purpose, the Trc reduction rate of uterine tissue of normal females was determined at a certain stage of the oestrous cycle and the observation was repeated at the same stage in a further cycle several

\footnotetext{
* This paper published with the approval of the Director as paper No. 1385, Journal Series, Agricultural Experiment Station, Lincoln.
} 
weeks later. The method of assessing the reaction rate is described by Schultze (1964). Groups of twenty-six females aged 85 to 100 days were used. In one group measurements of TTC reduction rate of the uterine tissue was made at two different pro-oestrous stages of the cycle. In another group the determinations were repeated at the oestrous stage and in another group at the 1-day post-oestrous stage. Statistical analysis of these data showed that there were significant differences $(P<0.01)$ between females with respect to the ability of their uterine tissue to reduce TTC to formazan. This was true whether the tests were carried out at the pro-oestrous stage, the oestrous stage or the 1-day post-oestrous stage of the cycle. Thus there appeared to be an individuality of the females' uterine tissue's ability to reduce TTC, which we termed the characteristic oestrogen status of the uterus.

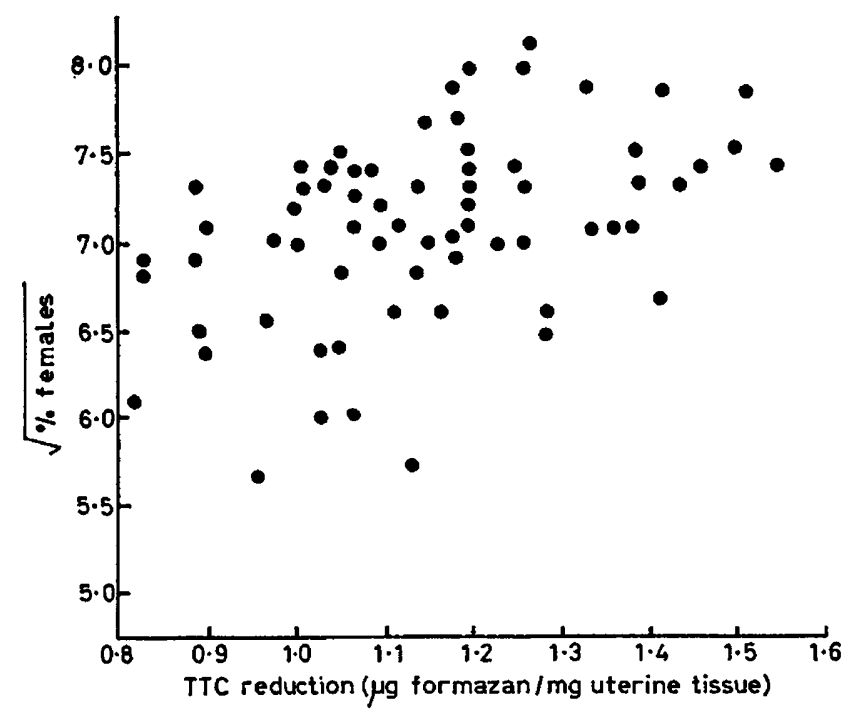

TexT-FIG. 1. Relationship between uterine Trc reduction rate in individual mothers and the percentage of females in their offspring.

The second part of this study was to determine whether there was a relation between the oestrogen status of the uterus of the female and her reproductive performance. Sixty-eight females were allowed to produce three litters each. The number of young and their sex were recorded for each litter. Size of the 204 litters varied from four to twenty young/litter. The average number per litter was 12.4 young. Following the weaning of the third litter and after the mothers were going through regular oestrous cycles, the uterine TTC reduction rate was determined in duplicate for each mother at the pro-oestrous stage of the cycle. The mean of the two determinations was taken as the individual's characteristic uterine oestrogen status; it varied from 0.80 to $1.55 \mu \mathrm{g}$ formazan/ $\mathrm{mg}$ uterine tissue/hr. The mean for the sixty-eight mothers was $1.15 \mu \mathrm{g}$ formazan $/ \mathrm{mg}$ tissue $/ \mathrm{hr}$.

The relationship between the values of the uterine TTC reduction rate for individuals and the size of the litters from those individuals was low and not 
statistically significant $(r=-0 \cdot 13)$. The relationship of the uterine TTC reduction rate of the mother and the percentage of females in the young dropped by her was highly significant $(r=+0 \cdot 38$, d.f. $=66)$. For analysis of these data, the square root of the percentage of females in the litter was used. The data are shown graphically in Text-fig. 1.

The equation expressing the regression of the square root of the percentage of females on TTG reduction of the mother's uterine tissue is $\hat{y}=5.84+0.011 x$, where $\hat{y}=$ the square root of the percentage of females in the litter, and $x=$ TTC reduction rate expressed in units of $0.01 \mathrm{\mu g}$ formazan $/ \mathrm{mg}$ uterine tissue $/ \mathrm{hr}$. The regression coefficient of 0.011 is highly significant according to the ' $t$ ' test. The regression equation indicates that mothers having low (80 units) and high (155 units) uterine TTC reduction values would be expected to have litters containing about $45 \%$ and $57 \%$ females respectively.

Modification of the sex ratio in rats has been accomplished (King, 1918) by selection and breeding for a high percentage female line and for a low percentage female line. Geiringer (1961) reported modification of the sex ratio in rats by administration of ACTH to mothers during early pregnancy. The number of females in the litters was increased by about $10 \%$ over that in control litters. Hahn \& Hays (1963) report modification of the sex ratio in rats by progesterone and oestrogen administration in ovariectomized females. Modification amounted to a difference of about $10 \%$ between experimental and control litters. Oestrogen administration resulted also in a decreased litter size. Geiringer noted no change in litter size with sex ratio modification, nor did King in her work. In our study, litter size was not significantly related to the uterine rate of reduction of TTC in individual mothers. If the assumption is made that sex ratio modification is due to preferential selection for one sex or the other by uterine environment, this selection process may operate on spermatozoa before the time of fertilization, since litter size appears to be unchanged in some cases.

In the reports cited above, the magnitude of change in sex ratio is similar to the modification found associated with the uterine TTC reaction rate of individuals in this study. The difference of 10 to $12 \%$ reported may indicate the limits of maternal influence on the sex ratio.

This work was supported by U.S. Public Health, National Institutes of Health grant.

\section{REFERENCES}

Geiringer, E. (1961) Effect of ACTH on sex ratio of the albino rat. Proc. Soc. exp. Biol., N.Y. 106, 752. HAHN, E. W. \& Hays, R. L. (1963) Modification of the secondary sex ratio in the albino rat by progesterone and oestrogen therapy. F. Reprod. Fertil. 6, 409.

KING, H. D. (1918) Studies on inbreeding. III. The effect of inbreeding with selection on the sex ratio of the albino rat. F. exp. Zool. $27,1$.

Martin, L. (1960) The use of 2-3-5-triphenyltetrazolium chloride in the biological assay of oestrogens. 7. Endocrin. 20, 187.

Schultze, A. B. (1964) Triphenyltetrazolium reduction by uterine tissue of rats. Proc. Soc. exp. Biol., N.r. 116, 653. 